\title{
Analisa Pola Kunjungan Wisatawan Ke Berbagai Objek Daya Tarik Wisata Di Pulau Ambon Menggunakan Frequent Pattern Growth
}

\author{
Muhammad Fadli Fakih ${ }^{*}$, Eko Mulyanto Yuniarno ${ }^{2}$, Supeno Mardi Susiki $\mathbf{N}^{3}$ \\ 1, 2, 3 Institut Teknologi Sepuluh Nopember \\ fadli_fakih@ymail.com ${ }^{* 1}$, ekomulyanto@ee.its.ac.id ${ }^{2}$, mardi@its.ac.id ${ }^{3}$
}

\begin{abstract}
Abstrak
Untuk menyusun perencanaan pengembangan objek daya tarik wisata di pulau Ambon khususnya penentuan pola perjalanan wisatawan diperlukan data dan Metode yang relevan, salah satu metode penentuan pola kunjungan wisata adalah Metode Frequent Pattern Growth yang terbukti dapat digunakan untuk melihat pola kecenderungan. Dari 505 sampel data wisatawan Gabungan yang terdiri dari 331 wisatawan Domestik dan 174 wisatawan mancanegara yang berkunjung ke 18 objek daya tarik wisata di pulau Ambon dengan minimum support $10 \%$ dan minimum confidence $70 \%$ didapatkan 12 pencarian pola kunjungan wisatawan yakni pola kunjungan wisatawan domestik, Mancanegara dan Gabungan ke seluruh ODTW, ODTW Pantai, ODTW Sejarah dan ODTW Alam. Dari masing-masing item, diambil 10 pola berdasarkan tingkat confidence tertinggi untuk dijadikan bahan rekomendasi bagi dinas terkait menyangkut penentuan pola kunjungan wisatawan di pulau Ambon.
\end{abstract}

Kata kunci: Pola Kunjungan, Wisatawan, Pulau Ambon, Frequent Pattern Growth

\begin{abstract}
To object development planning tourist attraction on the Ambon island in particular the determination of tourist travel patterns required data and methods that are relevant, one method of determining the pattern of tourist traffic is a method proven Frequent Pattern Growth can be used to see the pattern disposition. Of the 505 samples of the data rating Combined consisting of 331 Domestic tourists and 174 tourists Abroad visiting 18 attractions tourist attraction on the island of Ambon with a minimum support of $10 \%$ and a minimum of Confidence $70 \%$ obtained 12 search patterns for tourists visiting the pattern of tourist visits Domestic, Overseas and Combined throughout ODTW, ODTW Beach, ODTW ODTW History and Nature. Of each - each item, taken 10 patterns based on the highest confidence level to be used as recommendations for the relevant agencies regarding the determination of the pattern of tourist arrivals on the island of Ambon.
\end{abstract}

Keywords: Patterns Visits, Tourists, Ambon Island, Frequent Pattern Growth.

\section{Pendahuluan}

Pulau Ambon merupakan pulau yang terletak diantara Pulau Seram di sebelah utara, pulau Buru di sebelah barat dan kepulauan Banda di sebelah selatan [1]. Selain menjadi ibukota provinsi Maluku, pulau ini juga terdiri dari 2 daerah administratif, yaitu Kota Ambon dan Kabupaten Maluku Tengah. Data yang dirilis BPS kota Ambon di pulau ini terdapat lebih kurang 66 objek daya tarik wisata baik objek pantai, sejarah, maupun alam namun hanya lebih kurang 20 objek daya tarik wisata yang telah dikembangkan oleh pemerintah setempat maupun pihak swasta[1].

Data yang dirilis Dinas Pariwisata dan Ekonomi Kreatif Provinsi Maluku menunjukkan terjadi kenaikan kunjungan wisatawan ke pulau Ambon dari tahun ke tahun ini dapat dilihat dari tren kunjungan wisatawan dari tahun 2012 sampai 2015. Lebih dari separuh kunjungan wisatawan ke pulau Ambon adalah mengunjungi objek daya tarik wisata di pulau Ambon. Namun kenaikan jumlah kunjungan ke pulau Ambon tidak diimbangi dengan perbaikan infrastruktur pada objek daya tarik wisata dan peningkatan pelayanan oleh instansi terkait.

Untuk menyusun perencanaan pengembangan objek daya tarik wisata pulau Ambon khususnya penentuan pola perjalanan wisatawan diperlukan data dan informasi yang berkualitas. Fakih, M. (2017). Penentuan Pola Kunjungan Wisatawan Ke Berbagai Objek Wisata Di Pulau Ambon Menggunakan Frequent Pattern Growth. KINETIK, 2(3). doi:http://dx.doi.org/10.22219/kinetik.v2i3.46 Makalah dikirim 30 Juni 2017; Revisi 30 Juli 2017; Diterima 1 Agustus 2017 
Oleh karena itu dibutuhkan salah satu metode untuk penentuan pola kunjungan wisata dan Metode Frequent Pattern dapat digunakan untuk melihat pola kecenderungan. Adapun tujuan daripada penelitian ini adalah mendapatkan pola kunjungan wisatawan di pulau Ambon berdasarkan data kunjungan wisatawan ke kantor Dinas Pariwisata dan Ekonomi Kreatif Provinsi Maluku selama kurun waktu tahun 2014-2015 menggunakan Metode Frequent Pattern sehingga bisa dijadikan rekomendasi atau bahan pertimbangan bagi pemerintah daerah dan stake holder pariwisata untuk pengembangan strategi pemasaran dan promosi wisata pulau Ambon terkhusus pembuatan pola perjalanan wisata i travel pattern di pulau Ambon.

\section{Metode Penelitian}

Frequent Pattern Growth (FP-Growth) adalah salah satu algoritma association rules yang dikembangkan untuk menyelesaikan beberapa persoalan yang terdapat dalam algoritma Apriori. FP-Growth [2]-[4] termasuk dalam salah satu batu loncatan dalam pengembangan association rules mining. Dengan menggunakan FP-Growth, frequent item set Mining dapat dikerjakan tanpa melakukan candidate generation [3], [4]. FP-Growth menggunakan struktur data FP-Tree [5]-[7]. Dengan menggunakan cara ini scan database hanya dilakukan dua kali saja, tidak perlu berulangulang. Data akan direpresentasikan dalam bentuk FP-Tree. Setelah FP-Tree terbentuk, digunakan pendekatan divide and conquer untuk memperoleh frequent item set. FP-Tree merupakan struktur data yang baik sekali untuk Frequent Pattern Mining. Struktur ini memberikan informasi yang lengkap untuk membentuk Frequent Pattern. Item-item yang tidak frequent (infrequent) sudah tidak ada dalam FP-Tree [8]-[10]. Proses membangun FP-Tree adalah sebagai berikut:

1. Melakukan scan terhadap database, dalam tahap ini dihitung jumlah dari masing-masing item dalam transaksi. Dilakukan scan terhadap database untuk yang pertama kali. Hasil yang didapat adalah 1-item set yang paling sering muncul dalam transaksi.

2. Membuat FP-Tree berdasarkan 1-item set frequent yang didapat sebelumnya. FP-Tree yang dibentuk dinamakan root. Scan kedua dilakukan pada database untuk membangun FP-Tree. Untuk setiap transaksi dilakukan pengurutan kembali item berdasarkan 1-item set yang didapat.

3. Tahap pencarian frequent item set.

Data kunjungan wisatawan diperoleh dari Dinas Pariwisata dan Ekonomi kreatif Provinsi Maluku dalam bentuk Excel. Data ini di dapatkan dari laporan data survei kunjungan wisatawan dan data buku tamu wisatawan yang berkunjung ke Dinas Pariwisata dan Ekonomi Kreatif mulai tahun 2014 dan 2015. Pada tahap preprocessing dilakukan pengecekan kembali data yang akan diproses selanjutnya hal ini dilakukan untuk mencegah terjadinya pengulangan atau kesalahan data. Proses preprocessing terdiri dari dua tahap yang pertama adalah seleksi data dan yang kedua adalah transformasi data.

Dari data kunjungan wisatawan pada kantor Dinas Pariwisata dan Ekonomi Kreatif Provinsi Maluku tersebut kemudian dipisahkan dari data awal dan diambil data yang diperlukan untuk penelitian penentuan pola kunjungan wisatawan di pulau Ambon. Data kemudian di seleksi dan dibatasi dengan jumlah kunjungan wisatawan Mancanegara dan Domestik sebanyak 505 orang dan terdiri dari 18 objek daya tarik wisata yang dikunjungi dengan pembagian 6 objek wisata pantai, 6 objek wisata sejarah dan 6 objek wisata alam.

Pada penelitian ini, pola yang dicari adalah pola yang bersifat positif. Pola yang positif berarti hanya memperhatikan hubungan antar data yang bernilai " 1 " atau yang berarti benar. Proses perubahan data yang dilakukan adalah mengubah data tanda " $X$ " yang berarti berkunjung dan tanda "-" yang berarti tidak berkunjung menjadi data " 1 " yang artinya berkunjung dan " 0 " yang berarti tidak berkunjung. Perangkat lunak yang digunakan untuk mengolah data selanjutnya adalah Weka, sehingga data yang telah diubah disimpan kembali dalam format ARFF [2].

Secara garis besar alur kerja penelitian ini dapat digambarkan seperti Gambar 1. Setelah dilakukan tahapan preprocessing, selanjutnya data diolah menggunakan algoritma Frequent Pattern-Growth. Item yang digunakan adalah 18 objek daya tarik wisata dengan jumlah gabungan wisatawan Mancanegara dan Domestik berjumlah 505 wisatawan yang terdiri dari wisatawan Domestik berjumlah 331 dan wisatawan Mancanegara berjumlah 174. Proses untuk mendapatkan pola dengan menggunakan FP-Growth pada Gambar 2.

KINETIK Vol. 2, No. 3, Agustus 2017: 189-196 


\section{Mulai}

Pengambilan Data

\section{r}

\section{Pra Processing}

\section{Seleksi Data}

Transformasi Data

\section{Pencarian pola kunjungan wisatawan (Algoritma FP-Growth)}

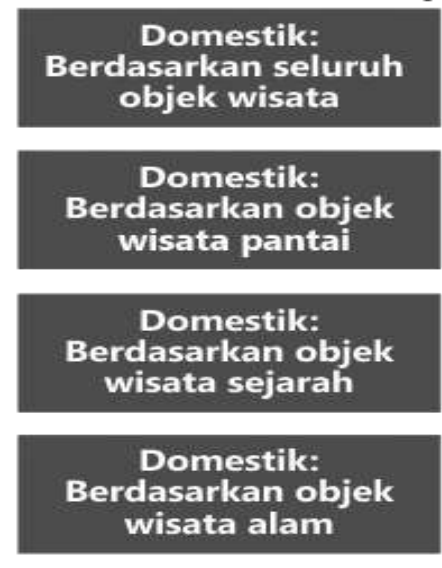

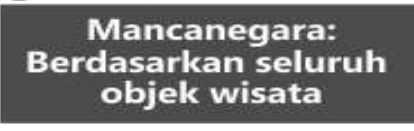
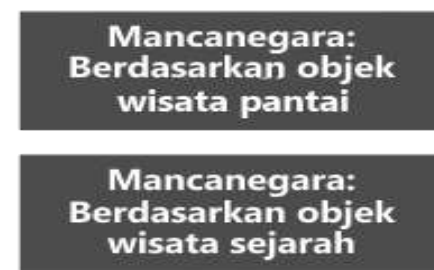
sejarah

Mancanegara:

Berdasarkan objek wisata alam

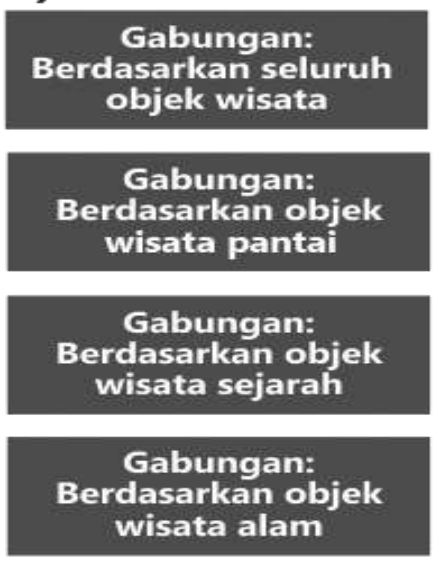

\section{Analisis pola kunjungan wisatawan}

(1)

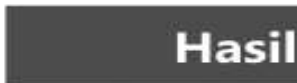

\section{Selesai}

Gambar 1. Alur Metodologi Penelitian
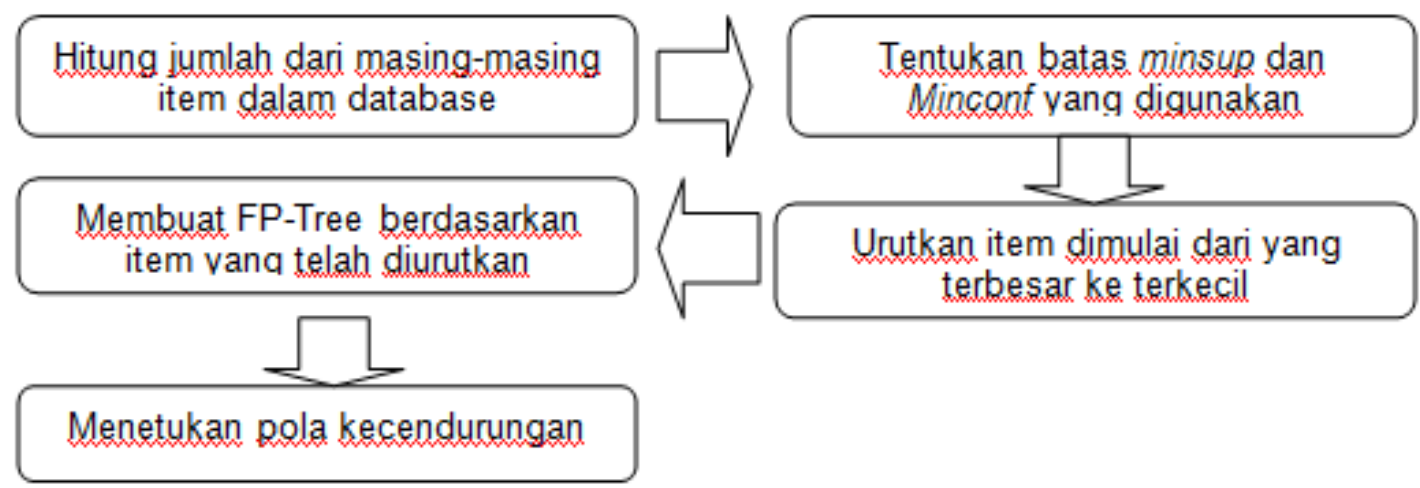

Gambar 2. Alur Algoritma FP-Growth 
Untuk pengolahan data selanjutnya digunakan perangkat lunak Weka 3.7. Pilihan menu yang ada pada Weka 3.7 untuk algoritma FP-Growth dapat dilihat pada Gambar 2. Nilai minimum support yang digunakan pada penelitian ini adalah 10 persen. Nilai minimum confidence untuk masing-masing kelompok ditetapkan sebesar 70 persen.

Pola yang didapatkan memperhitungkan batasan minimal support yang telah ditetapkan dan diurutkan berdasarkan besarnya nilai confidence. Pada pengolahan data selanjutnya, dalam penelitian ini menggunakan algoritma FP-Growth pada perangkat lunak Weka. Adapun persamaan untuk mencari support dan confidence seperti pada Persamaan 1 dan Persamaan 2.

$$
\begin{gathered}
\text { Support }=\frac{\sum \text { Jumlah wisatawan ke objek yang dikunjungi sekaligus }}{\sum \text { Jumlah totl wisatawan yang berkunjung }} \\
\text { Confidence }=\frac{\sum \text { Jumlah wisatawan ke objek yang dikunjungi sekaligus }}{\sum \text { Jumlah kunjungan wisatawan pada objek atecendent }}
\end{gathered}
$$

\section{Hasil Penelitian dan Pembahasan}

Contoh hasil pengolahan data menggunakan algoritma FP-Growth pada data kunjungan wisatawan gabungan ke objek daya tarik wisata pantai di pulau Ambon adalah sebagai berikut:

1. Jumlah total wisatawan gabungan yang berkunjung ke objek daya tarik wisata pantai di pulau Ambon sebanyak 505 orang dengan jumlah objek kunjungan sebanyak enam.

2. Nilai minimal support yang ditetapkan sebesar 10 persen (50 wisatawan). Item yang mempunyai jumlah lebih dari batas minimal support yang telah ditetapkan adalah: Pantai Liang, Pantai Namalatu, Pantai Pintu Kota, Pantai Hukurila, Pantai Natsepa, Pantai Collins

3. Berdasarkan jumlah item dalam database, jika diurutkan dari jumlah terbesar ke terkecil, urutan itemnya menjadi:
1. Pantai Liang
: 405 wisatawan
2. Pantai Namalatu
: 383 wisatawan
3. Pantai Pintu Kota
: 337 wisatawan
4. Pantai Hukurila
: 321 wisatawan
5. Pantai Natsepa
: 305 wisatawan
6. Pantai Collins
: 53 wisatawan

4. FP-Tree yang dihasilkan berdasarkan item yang telah diurutkan sebelumnya dapat dilihat pada Gambar 3.

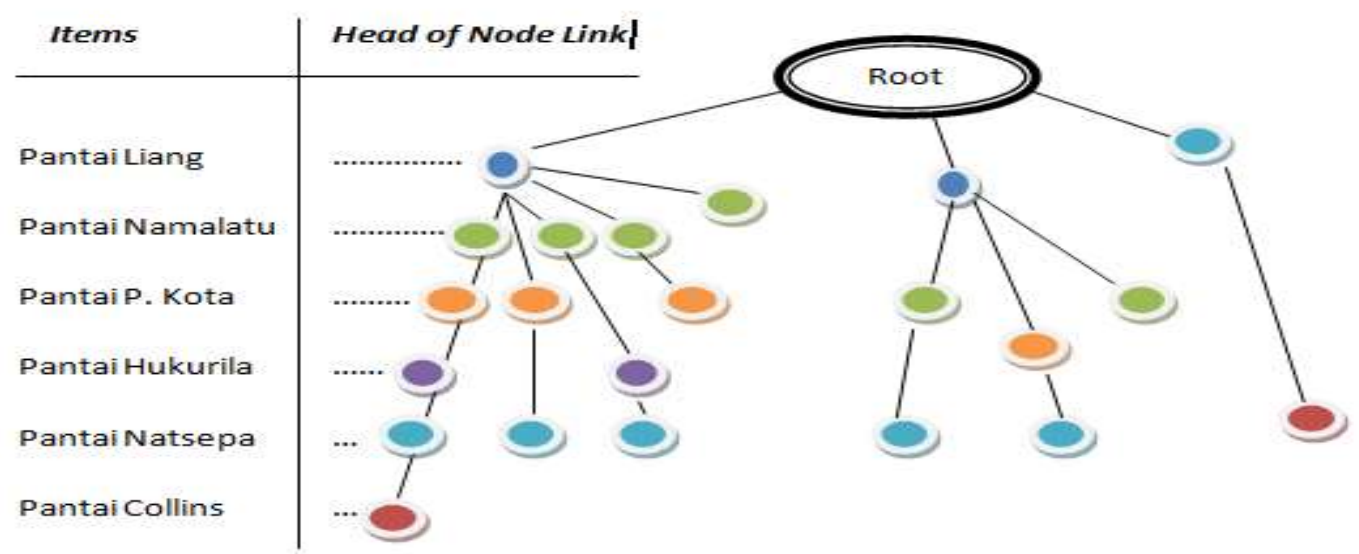

Gambar 3. FP-Tree Kunjungan Wisatawan Gabungan ke ODTW Wisata Pantai

Jumlah dari masing-masing item set yang telah tertera pada FP-Tree dapat dilihat penjelasannya pada Tabel 1. Setelah mendapatkan FP-Tree, langkah selanjutnya adalah menentukan pola berdasarkan kombinasi item set yang terdapat pada FP-Tree. Contoh ekstraksi pola yang didapatkan pada kunjungan wisatawan gabungan ke objek daya tarik wisata pantai di pulau Ambon dapat dilihat pada Tabel 2.

KINETIK Vol. 2, No. 3, Agustus 2017: 189-196 
Tabel 1. Jumlah Kunjungan Wisatawan Pada Masing-Masing Item Set

\begin{tabular}{clc}
\hline Nomor & \multicolumn{1}{c}{ Item set } & Wisatawan \\
\hline$(1)$ & \multicolumn{1}{c}{$(2)$} & $(3)$ \\
\hline 1 & Pantai Namalatu $\rightarrow$ Pantai Hukurila $\rightarrow$ Pantai Natsepa & 121 \\
\hline 2 & Pantai Namalatu $\rightarrow$ Pantai Natsepa $\rightarrow$ Pantai Liang & 193 \\
\hline 3 & Pantai Namalatu $\rightarrow$ Pantai Pintu Kota $\rightarrow$ Pantai Natsepa $\rightarrow$ & 161 \\
& Pantai Liang & 125 \\
\hline 4 & Pantai Pintu Kota $\rightarrow$ Pantai Hukurila $\rightarrow$ Pantai Natsepa $\rightarrow$ & 268 \\
\hline 5 & Pantai Liang & 166 \\
\hline 6 & Pantai Natsepa $\rightarrow$ Pantai Liang & 203 \\
\hline 8 & Pantai Hukurila $\rightarrow$ Pantai Natsepa $\rightarrow$ Pantai Liang & 197 \\
\hline 9 & Pantai Pintu Kota $\rightarrow$ Pantai Natsepa $\rightarrow$ Pantai Liang & 127 \\
\hline 10 & Pantai Namalatu $\rightarrow$ Pantai Pintu Kota $\rightarrow$ Pantai Hukurila $\rightarrow$ \\
\hline
\end{tabular}

Tabel 2. Ekstraksi Pola Kunjungan Wisatawan Gabungan ke ODTW Pantai

\begin{tabular}{clccc}
\hline Pola & \multicolumn{1}{c}{ Antecedent } & Consequent & $\begin{array}{c}\text { Support } \\
(\%)\end{array}$ & $\begin{array}{c}\text { Confidence } \\
(\%)\end{array}$ \\
\hline \multicolumn{1}{c}{$($ 1) } & \multicolumn{1}{c}{$($ 2) } & \multicolumn{1}{c}{$(3)$} & $(4)$ & $(5)$ \\
\hline Pola 1 & $\begin{array}{l}\text { Pantai Namalatu, Pantai Hukurila, } \\
\text { Pantai Natsepa }\end{array}$ & Pantai Liang & 23.96 & 89.62 \\
\hline Pola 2 & Pantai Namalatu, Pantai Natsepa & Pantai Liang & 38.21 & 89.35 \\
\hline Pola 3 & $\begin{array}{l}\text { Pantai Namalatu, Pantai Pintu } \\
\text { Kota, Pantai Natsepa }\end{array}$ & Pantai Liang & 31.88 & 88.81 \\
\hline Pola 4 & $\begin{array}{l}\text { Pantai Pintu Kota, Pantai Hukurila, } \\
\text { Pantai Natsepa }\end{array}$ & Pantai Liang & 24.75 & 88.02 \\
\hline Pola 5 & Pantai Natsepa & Pantai Liang & 53.06 & 87.86 \\
\hline Pola 6 & Pantai Hukurila, Pantai Natsepa & Pantai Liang & 32.87 & 87.36 \\
\hline Pola 7 & Pantai Pintu Kota, Pantai Natsepa & Pantai Liang & 40.19 & 87.12 \\
\hline Pola 8 & $\begin{array}{l}\text { Pantai Namalatu, Pantai Pintu } \\
\text { Kota }\end{array}$ & Pantai Liang & 39.00 & 84.18 \\
\hline Pola 9 & $\begin{array}{l}\text { Pantai Namalatu, Pantai Pintu } \\
\text { Kota, Pantai Hukurila }\end{array}$ & Pantai Liang & 25.14 & 83.00 \\
\hline Pola 10 & Pantai Pintu Kota & Pantai Liang & 54.65 & 81.89 \\
\hline
\end{tabular}

Adapun pola kunjungan wisatawan yang dicari pada penelitian ini berjumlah 12 hasil pola tertinggi dari 12 pola kunjungan tersebut antara lain:

1. Pola kunjungan wisatawan Domestik ke seluruh Objek Daya Tarik Wisata (ODTW) didapatkan jika wisatawan berkunjung ke pantai Natsepa maka wisatawan itu pula akan berkunjung ke pantai Liang dengan hasil support $=52.87 \%$ dan hasil confidence $=89.74 \%$.

2. Pola kunjungan wisatawan Domestik ke ODTW pantai didapatkan jika wisatawan berkunjung ke pantai Hukurila dan Pantai Natsepa maka wisatawan akan berkunjung ke pantai Liang dengan hasil support $=33.53 \%$ dan hasil confidence $=90.24 \%$.

3. Pola kunjungan wisatawan Domestik ke ODTW sejarah didapatkan jika wisatawan berkunjung ke Museum Siwalima dan Gereja Tua Hila maka wisatawan akan berkunjung ke Gong perdamaian dengan hasil support $=10.87 \%$ dan hasil confidence $=83.72 \%$.

4. Pola kunjungan wisatawan Domestik ke ODTW alam didapatkan jika wisatawan berkunjung ke Air Panas Tulehu maka wisatawan akan berkunjung ke Morea Waai dengan hasil support $=11.17 \%$ dan hasil confidence $=38.94 \%$.

5. Pola kunjungan wisatawan Mancanegara ke seluruh ODTW didapatkan jika wisatawan berkunjung ke pantai Pintu Kota dan Pantai Natsepa maka wisatawan akan berkunjung ke Museum Siwalima dengan hasil support $=48.27 \%$ dan hasil confidence $=91.30 \%$. 
6. Pola kunjungan wisatawan Mancanegara ke ODTW pantai didapatkan jika wisatawan berkunjung ke pantai Namalatu dan Pantai Natsepa maka wisatawan juga berkunjung ke pantai Liang dengan hasil support $=36.20 \%$ dan hasil confidence $=90.00 \%$.

7. Pola kunjungan wisatawan Mancanegara ke ODTW sejarah didapatkan jika wisatawan berkunjung ke Gereja Tua Hila maka wisatawan tentu berkunjung ke Museum Siwalima dengan hasil support $=17.24 \%$ dan hasil confidence $=90.90 \%$.

8. Pola kunjungan wisatawan Mancanegara ke ODTW alam didapatkan jika wisatawan berkunjung ke Morea Waai maka wisatawan berkunjung ke Tanjung Setan dengan hasil support $=65.51 \%$ dan hasil confidence $=95.00 \%$.

9. Pola kunjungan wisatawan Gabungan ke seluruh ODTW didapatkan jika wisatawan berkunjung ke pantai Natsepa maka wisatawan akan berkunjung ke pantai Liang dengan hasil support $=53.06 \%$ dan hasil confidence $=87.86 \%$.

10. Pola kunjungan wisatawan Gabungan ke ODTW pantai didapatkan jika wisatawan berkunjung ke pantai Namalatu, Pantai Hukurila dan Pantai Natsepa maka wisatawan tentu berkunjung ke pantai Liang dengan hasil support $=23.96 \%$ dan hasil confidence $=89.62 \%$.

11. Pola kunjungan wisatawan Gabungan ke ODTW sejarah didapatkan jika wisatawan berkunjung ke Gereja Tua Hila maka wisatawan akan berkunjung ke Museum Siwalima dengan hasil support $=14.45 \%$ dan hasil confidence $=82.95 \%$.

12. Pola kunjungan wisatawan Gabungan ke ODTW alam didapatkan jika wisatawan berkunjung ke Taman Laut Pulau Pombo maka wisatawan juga akan berkunjung ke Tanjung Setan dengan hasil support $=76.23 \%$ dan hasil confidence $=92.54 \%$.

Perbandingan gambaran pola kunjungan wisatawan Gabungan ke berbagai objek daya tarik wisata di pulau Ambon secara manual dengan menggunakan FP-Growth. Pada gambar 4. Yang merupakan data manual hasil workshop tim penyusun pola perjalanan wisata di pulau Ambon (Travel Pattern) tahun 2013, disitu menunjukkan banyak dan lamanya waktu tempuh untuk mengunjungi masing-masing objek daya tarik wisata di pulau Ambon yang sedikit bertolak belakang dengan keinginan tour dari wisatawan yang memiliki waktu singkat untuk dipulau Ambon (1 x 24 jam). Untuk menyiasati hal tersebut dibuatlah paket tour singkat berdasarkan pola kunjungan wisatawan terbanyak ke berbagai objek daya tarik wisata pulau Ambon menggunakan metode FP-Growth adapun contoh hasil gambaran wisatawan Gabungan menggunakan FPGrowth dapat dilihat pada Gambar 5. Dari hasil FP-Growth didapatkan pola kunjungan wisatawan Gabungan singkat yang berkunjung ke beberapa objek daya tarik wisata di pulau Ambon.

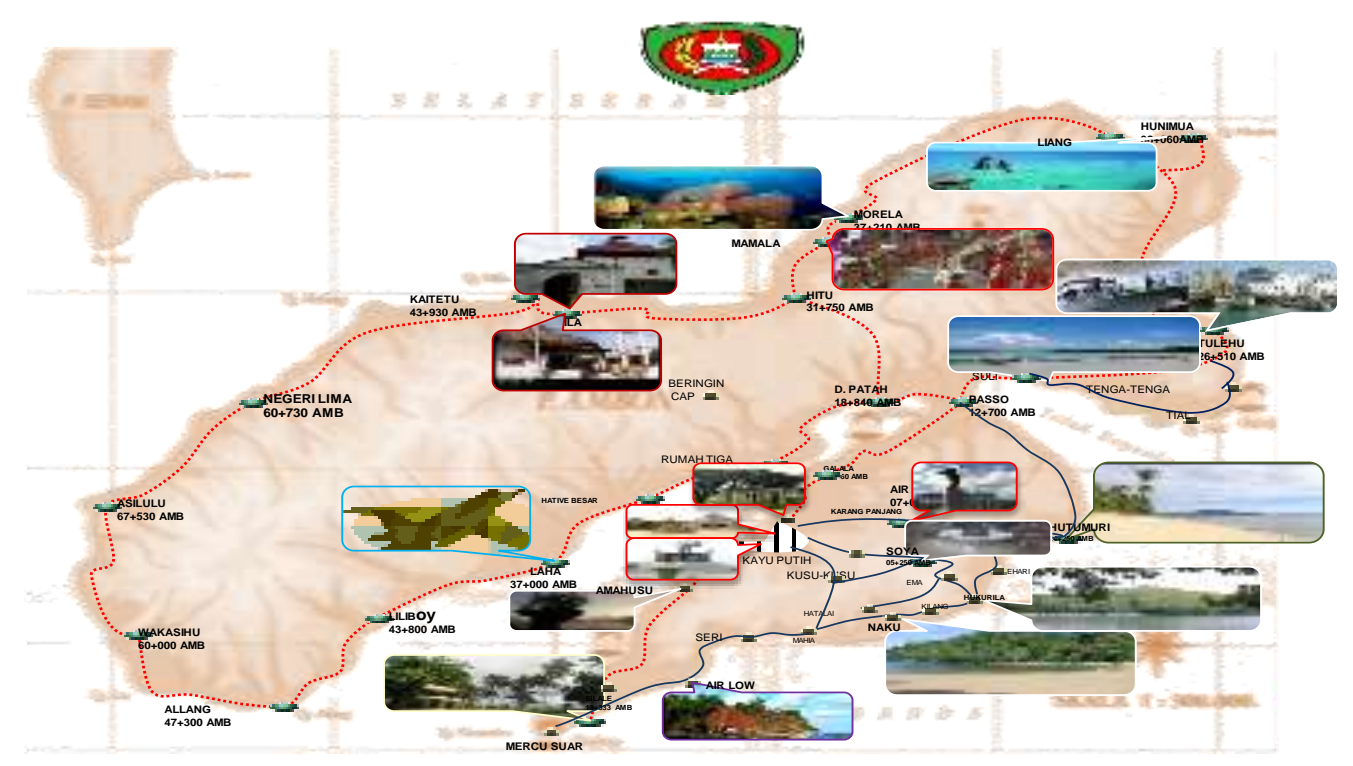

Gambar 4. Kunjungan Wisatawan Gabungan ke Berbagai ODTW 


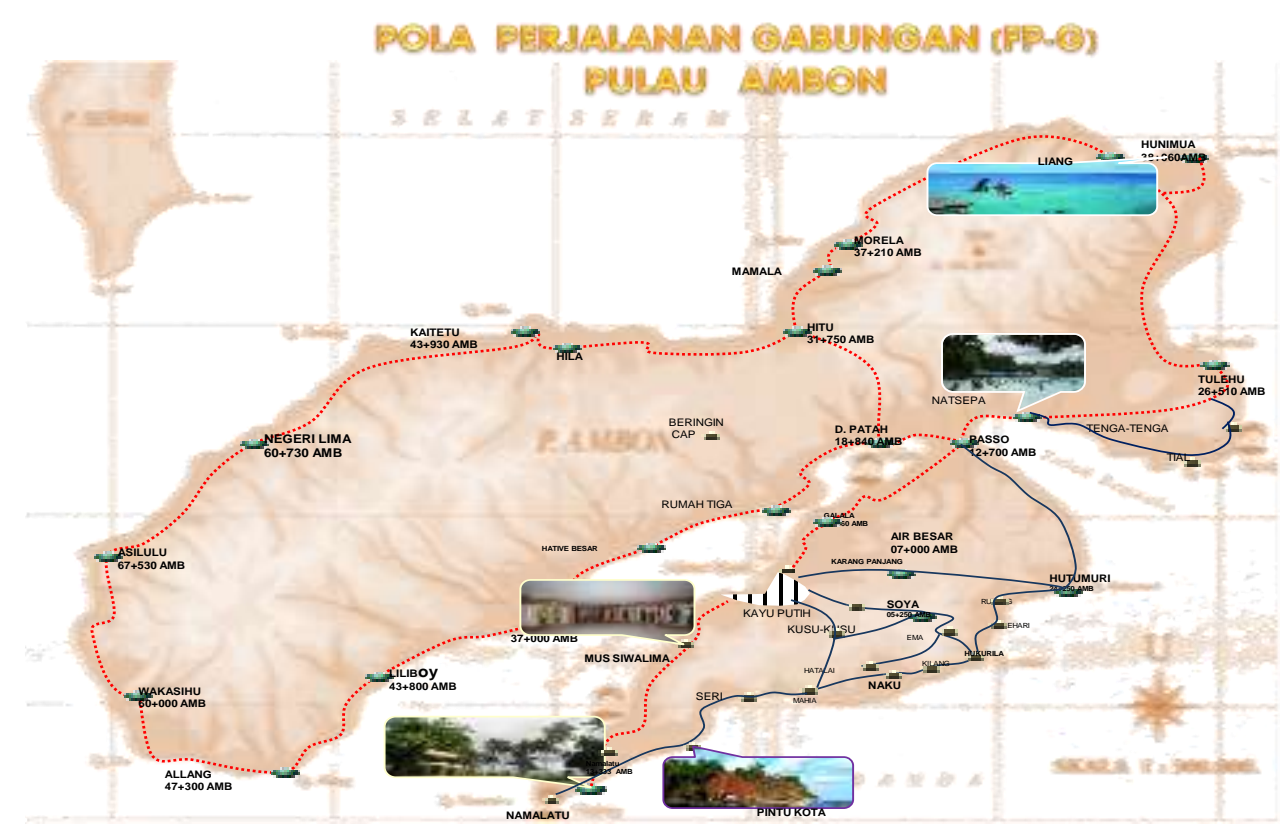

Gambar 5. Kunjungan Wisatawan Gabungan ke Berbagai ODTW Menggunakan FP-Growth

\section{Kesimpulan}

Kesimpulan dari penelitian ini adalah Metode Frequent Pattern Growth dapat digunakan untuk mencari/menentukan pola kunjungan wisatawan dari sebelumnya memiliki rute panjang dan bersifat manual menjadi rute singkat/pendek dengan menggunakan metode FP-Growth. Adapun hasil yang didapatkan diharapkan menjadi bahan pertimbangan kepada dinas terkait terutama dalam pembuatan pola kunjungan/perjalanan wisata singkat di pulau Ambon. Ke depannya diharapkan diadakan penelitian lebih lanjut demi kesempurnaan penelitian yang telah dilakukan.

\section{Daftar Notasi dan istilah}
$\sum \quad$ : jumlah
Antecedent : yang diawali atau yang didahului oleh
Consequent : yang diakhiri oleh
Support : dukungan antara satu objek dengan objek lainnya
Confidence : keyakinan
Pola : bentuk

\section{Referensi}

[1] J. Ariati, I. Ibrahim, "Sebaran Habitat Perkembangbiakan Larva Anopheles Spp Di Kecamatan Bula, Kabupaten Seram Bagian Timur, Provinsi Maluku," Jurnal Ekologi, 2014.

[2] J. Han, J. Pei, Y. Yin, R. Mao, "Mining Frequent Patterns Without Candidate Generation: A Frequent-Pattern Tree Approach," Data Mining and Knowledge Discovery, 2004.

[3] J. Han, J. Pei, "Mining Frequent Patterns By Pattern-Growth: Methodology And Implications," ACM SIGKDD Explorations Newsletter, 2000.

[4] J. Pei, J. Han, "Constrained frequent pattern mining: a pattern-growth view," ACM SIGKDD Explorations Newsletter, 2002.

[5] E. Rachman, A. Bachtiar, "Penerapan Data Mining Dalam Perekomendasian Setelan Busana Muslim Dengan Metode Association Rules Menggunakan," KNTIA, 2017.

[6] A. Wijaksono, H. Santoso, "Penentuan Lokasi Barang Pada 'A Swalayan' Menggunakan Association Rule Dengan Algoritma FP-Growth," SISITI Seminar, 2017.

[7] P. Lintang, M. Iqbal, A. Pujianto, "Sistem Rekomendasi Paket Makanan Dengan Algoritma FP-Growth Pada Restoran Seafood XYZ," SEMNASTEKNOMEDIA ONLINE, 2017. 
[8] M. Robin, A. Rasel, A. Siddika, "An Efficient Approach to Mine Frequent Itemsets Using the Variant of Classic Apriori and FP-Tree," 2017.

[9] R. Krupali, D. Garg, "Survey on the Techniques of FP-Growth Tree for Efficient Frequent Item-set Mining," International Journal of Computer, 2017.

[10] L. Yuan, W. Itwee, S. Wei, "Association Rule Mining Technique with Optimized FP-Tree Algorithm," International Journal of Advanced, 2017. 